OPEN ACCESS

Edited by:

Lin Chen

PLA General Hospital, China

Reviewed by:

Yoshiharu Sakai,

Kyoto University, Japan

Song Wu,

First Affiliated Hospital of Sun Yat-sen

University, China

*Correspondence:

Chen Huang

richard-hc@hotmail.com

Specialty section:

This article was submitted to

Surgical Oncology,

a section of the journal

Frontiers in Oncology

Received: 11 March 2019 Accepted: 18 November 2019 Published: 06 December 2019

Citation:

Luo Z, Rong Z and Huang C (2019) Surgery Strategies for Gastric Cancer

With Liver Metastasis.

Front. Oncol. 9:1353.

doi: 10.3389/fonc. 2019.01353

\section{Surgery Strategies for Gastric Cancer With Liver Metastasis}

\author{
Zai Luo, Zeyin Rong and Chen Huang* \\ Department of General Surgery, Shanghai General Hospital, School of Medicine, Shanghai Jiao Tong University, Shanghai, \\ China
}

Gastric cancer with liver metastasis is defined as advanced gastric cancer and remains one of the deadliest diseases with poor prognosis. Approximately $4-14 \%$ of patients with gastric cancers presented with liver metastases at the initial diagnosis. Owing to its incurability, first-line treatment for gastric cancer with liver metastases is systematic chemotherapy, whereas surgery is usually performed to alleviate severe gastrointestinal symptoms. However, continuously emerging retrospective studies confirmed the role of surgery in gastric cancer with liver metastases and showed significantly improved survival rate in patients assigned to a group of surgery with or without chemotherapy. Therefore, more and more convincing data that resulted from prospective randomized clinical trials is in need to clarify the surgery strategies in patients with gastric cancer with liver metastasis.

Keywords: gastric cancer, liver metastasis, surgery, strategy, R0 resection

\section{INTRODUCTION}

Gastric cancer (GC), as the third most frequent cause of cancer-related death for human cancers in the world, continues to carry a noticeably higher fatality-to-case ratio, accounting for exceeding 782,000 confirmed cases died in 2018 worldwide (1). Especially in China, based on data from National Central Cancer Registry of China (NCCR) in 2015, gastric cancer was the most common cancer and the leading cause of cancer death except for lung cancer (2). Predominantly due to late-onset and non-specific symptoms and lack of active screening programs, $\sim 34 \%$ of patients have distant metastases according to the Surveillance, Epidemiology, and End Results (SEER) Database (3), and nearly $4-14 \%$ of patients present with liver metastases at the initial presentation (4). In fact, the leading causes of death for gastric cancer include local recurrence, gross peritoneal dissemination, direct invasion to other organs, and extensive distant organ metastases. Anatomically speaking, the liver is the most common site of hematogenous metastases for advanced gastric cancer. Gastric cancer with liver metastases (GCLM) is generally classified into two types: one is synchronous metastases, which defined as metastases occurring before or during surgery or within 6 months after gastrectomy, and the other is metachronous metastases, which defined as metastases identified at least 6 months after gastrectomy (5). Synchronous GCLM is detected in nearly $5-10 \%$ of gastric cancer patients at diagnosis (6), whereas metachronous GCLM is in up to $37 \%$ after "curative" resection of primary gastric cancer (7).

According to practical clinical guidelines, such as the National Comprehensive Cancer Network (NCCN), GCLM was regarded as stage IVb disease and unresectable tumor, which not only showed aggressive oncological behavior but also accompanied by distant metastases. And it was traditionally recommended with systemic chemotherapy including CF (cisplatin and fluorouracil) or ECF (epirubicin, cisplatin, and fluorouracil) chemotherapeutic regimens 
(8). Recently, accumulating clinical trials have achieved significant progress in chemotherapy. For example, for HER2negative advanced gastric cancer, the findings of the SPIRITS trial revealed the superiority of S-1 plus cisplatin to S- 1 alone in advanced gastric cancer (9). Furthermore, results of the G-SOX trial found that S-1 plus oxaliplatin was non-inferior to S-1 plus cisplatin in advanced gastric cancer, mainly in less toxic and more convenient clinically (10). For HER2-positive advanced gastric cancer, discoveries of the ToGA trial found that chemotherapy regimen consisting of capecitabine plus or fluorouracil plus cisplatin in combination with trastuzumab was a promising option for patients with HER2-positive advanced gastric cancer (11). In addition, results of the ATTRACTION-2 trial indicated the survival benefits of nivolumab in patients with advanced gastric or gastroesophageal junction cancer (12). Although major progress was made in chemotherapy and molecularly targeted biological therapy $(13,14)$, until now, the median survival time (MST) of patients with GCLM was between 7 and 14.1 months (9-12). Given the dismal prognosis of patients with GCLM, there was an urgent need to develop better treatment strategies for GCLM in the absence of institutional guidelines or protocols.

Inspired by substantial survival benefits and compelling evidence of surgery in patients with colorectal cancer liver metastases $(15,16)$, many clinical surgeons explored the role of surgery in GCLM, which was considered as a crucial intervention and the most essential step to cure disease and to prolong patient life (17). Increasing systemic and aggressive oncological behaviors were shown in GCLM (18), compared with colorectal cancer liver metastases; gastrectomy was reserved for the palliation of severe gastrointestinal symptoms such as refractory hemorrhage and obstruction in patients with GCLM based on NCCN (8). On the contrary, the Guidelines Committee of the Japan Gastric Cancer Association was in favor of surgical resection of potentially resectable M1 disease (19), and recent studies showed that the potential of surgical resection in selected GCLM, which can bring MST between 9 and 67.5 months and 5 -year survival, varies from 0 to $42 \%$, inspiringly $(5,20,21)$. This review aims to summarize recent studies underpinning the surgical resection for GCLM and to explain the surgery strategies in different clinical classifications of GCLM.

\section{CURRENT EVIDENCE}

\section{Controversies in the Surgical Resection of Gastric Cancer With Liver Metastasis}

From the perspective of the routine clinical application, objective assessments of clinical data about surgical resection in GCLM are essential to investigate the surgery strategies in GCLM. Although surgery is recommended to alleviate severe gastrointestinal symptoms in consensus, the utility of surgery in GCLM still remains highly controversial. More recently, inconsistent and contradictory findings of surgical resection in GCLM have emerged in published literature $(22,23)$.

A public clinical trial (REGATTA) (22) failed to improve the overall survival (OS) rate in advanced gastric cancer patients assigned to gastrectomy plus post-operative chemotherapy than in those assigned to chemotherapy alone (14.3 vs. 16.6 months). However, evidence from a clinical trial (AIO-FLOT3) (23) showed different outcomes. Compared with patients who experienced chemotherapy alone, patients who experienced neoadjuvant chemotherapy followed by surgical resection had superior OS (22.9 vs. 10.7 months). Notably, the design of the REGATTA trial differed from the design of the AIOFLOT3 trial in some respects, which possibly had influenced outcomes of the trial. First, most GCLM patients enrolled in the REGATTA trial were accompanied by peritoneal metastases, who were recognized as the worst kind in advanced GC patients in prognosis. Second, the surgical management in the REGATTA trial was restricted to D1 lymphadenectomy only, whereas in the AIO-FLOT3 trial, the surgical management adopted gastrectomy with D2 lymphadenectomy, which was recommended for total or subtotal distal gastrectomy (24). Third, compared with gastrectomy plus chemotherapy adopted in the REGATTA trial, the AIO-FLOT3 trial utilized neoadjuvant chemotherapy followed by surgical resection in the treatment plan. Collectively, the above evidence reveals the crucial factors including patient selection, surgical procedures, and treatment options in a multimodality approach to GCLM.

\section{Potential Superiority of Surgery in Gastric Cancer With Liver Metastasis}

Available evidence of surgery for patients with GCLM mostly relies on retrospective studies, systematic reviews, and prospective trials. Data published after 2000 mostly showed significant and prognostic benefits of surgical resection for GCLM (Table 1) $(5,6,20,21,25,73)$, and the benefits were in continuous increase owing to advancements in accurate diagnosis, patient selection, perioperative nutritional support, anesthetic techniques, surgery approaches, management of post-operative complications, and enhanced recovery after surgery.

Recently, principally from East Asia and Europe, large retrospective studies on the surgical resection of GCLM have shown continuously acceptable survival outcomes for selected patients. Nishi et al. (51) demonstrated that the overall 1- and 3-year survival rates after hepatic resection for GCLM were 88.9 and $17.8 \%$ in 10 selected patients, respectively, with an MST of 21.5 months and no post-operative mortality. Similarly, in a retrospective single-center study involving 34 patients with GCLM, Ryu et al. (59) investigated the significance of surgical procedures including hepatic resection for more massive metastases and surgical microwave ablation for patients who had a high operative risk and identified prognostic factors. The results showed acceptable morbidity and favorable long-term outcomes, as the 1-, 3-, and 5-year OS rates after surgery were $86.5,51.4$, and $42.1 \%$, respectively, and the 1-, 3-, and 5-year recurrence-free survival (RFS) rates were $38.5,28.0$, and $28.0 \%$, respectively, with no significant survival differences for varied surgical treatments $(P=0.213)$.

Meanwhile, a nationwide retrospective study from England also showed that gastrectomy combined with hepatectomy for synchronous GCLM might carry survival benefits in 
TABLE 1 | Demographics and survival in GCLM patients underwent surgical resection.

\begin{tabular}{|c|c|c|c|c|c|c|c|c|c|c|c|}
\hline \multirow[t]{2}{*}{ References } & \multirow[t]{2}{*}{ Year } & \multirow[t]{2}{*}{ Country } & \multirow[t]{2}{*}{ Type } & \multirow{2}{*}{$\begin{array}{l}\text { Study } \\
\text { interval }\end{array}$} & \multirow{2}{*}{$\begin{array}{c}\text { No. of } \\
\text { Patients }\end{array}$} & \multirow{2}{*}{$\begin{array}{c}\text { Median } \\
\text { Age }\end{array}$} & \multirow{2}{*}{$\begin{array}{c}\text { Post-operative } \\
\text { 30-day mortality } \\
\text { (\%) }\end{array}$} & \multicolumn{4}{|c|}{ Overall survival } \\
\hline & & & & & & & & 1 year $(\%)$ & 3 years (\%) & 5 years $(\%)$ & $\begin{array}{c}\text { MST } \\
\text { (months) }\end{array}$ \\
\hline Adam et al. (25) & 2006 & France & Retro & 1983-2004 & 64 & NR & $N R$ & $N R$ & NR & 27 & 15 \\
\hline Aizawa et al. (26) & 2014 & Japan & Retro & 1997-2010 & 53 & 66 & NR & $N R$ & NR & 18.6 & 27.4 \\
\hline Ambiru et al. (27) & 2001 & Japan & Retro & 1975-1999 & 40 & 63 & 0 & $N R$ & $N R$ & 18 & 12 \\
\hline Baek et al. (28) & 2013 & Korea & Retro & 2003-2010 & 12 & 61 & 0 & 65 & $N R$ & 39 & 31 \\
\hline Chen et al. (29) & 2013 & China & Retro & 2007-2012 & 20 & 57 & 0 & $N R$ & $N R$ & 15 & 22.3 \\
\hline Cheon et al. (30) & 2008 & Korea & Retro & 1995-2005 & 41 & 60 & 1.72 & 75 & 32 & 21 & 17 \\
\hline Choi et al. (31) & 2010 & Korea & Retro & 1986-2007 & 14 & 65 & NR & 67 & 38.3 & $\mathrm{NR}$ & NR \\
\hline Dittmar et al. (32) & 2012 & Germany & Retro & 1995-2009 & 15 & 57 & 0 & $N R$ & NR & 27 & 48 \\
\hline Fukami et al. (33) & 2017 & Japan & Retro & 2001-2012 & 14 & 66 & $N R$ & 71.4 & 42.9 & 42.9 & 27.9 \\
\hline Fuji et al. (34) & 2001 & Japan & Retro & 1979-1999 & 10 & 58.5 & 10 & 60 & 20 & 10 & $N R$ \\
\hline Garancini et al. (35) & 2012 & Italy & Retro & 1998-2007 & 21 & 64 & 0 & 68 & 31 & 19 & 11 \\
\hline Guner et al. (36) & 2016 & Korea & Retro & 1998-2013 & 68 & 61 & $N R$ & 79.1 & 40.6 & 30 & $N R$ \\
\hline Hirai et al. (37) & 2006 & Japan & Retro & 1993-2004 & 14 & NR & NR & $N R$ & $\mathrm{NR}$ & 41.6 & NR \\
\hline Hwang et al. (38) & 2009 & Korea & Retro & 1995-2005 & 73 & 59 & NR & $N R$ & NR & $N R$ & 20 \\
\hline Imanura et al. (39) & 2001 & Japan & Retro & 1990-1997 & 17 & NA & NR & 60 & 25 & NR & NR \\
\hline Kinoshita et al. (40) & 2015 & Japan & Retro & 1990-2010 & 256 & 64 & NR & 77.3 & 41.9 & 31.1 & 31.1 \\
\hline Koga et al. (41) & 2007 & Japan & Retro & 1985-2005 & 42 & 64 & 0 & 76 & 48 & 42 & 34 \\
\hline Kokkola et al. (42) & 2012 & Finland & Retro & 2000-2009 & 23 & 61.4 & $N R$ & $N R$ & $N R$ & NR & 14.3 \\
\hline Komeda et al. (43) & 2014 & Japan & Retro & 2000-2012 & 24 & 69.5 & 0 & 78.3 & 40.1 & 40.1 & 22.3 \\
\hline Lee et al. (20) & 2017 & Korea & Retro & 2000-2014 & 7 & 59.2 & NR & $N R$ & $N R$ & 68.6 & 67.5 \\
\hline Li et al. (6) & 2015 & China & Retro & 2008-2011 & 25 & 61.4 & $N R$ & 72 & NR & NR & 20.5 \\
\hline Li et al. (44) & 2017 & China & Retro & 1996-2012 & 34 & 62 & NR & 73.5 & 36.9 & 24.5 & 26.2 \\
\hline Liu et al. (45) & 2012 & China & Retro & 1995-2010 & 35 & NR & NR & 58.1 & 21.7 & $\mathrm{NR}$ & 15 \\
\hline Liu et al. (46) & 2015 & China & Retro & 1990-2009 & 35 & 56 & 0 & NR & $N R$ & 14.3 & 33 \\
\hline Makino et al. (47) & 2010 & Japan & Retro & 1992-2007 & 16 & NA & 0 & 82.3 & 46.4 & 37.1 & 31.2 \\
\hline Markar et al. (48) & 2016 & UK & Retro & 1997-2012 & 78 & NR & 7.2 & 64.1 & NR & 38.5 & $N R$ \\
\hline Miki et al. (49) & 2012 & Japan & Retro & 1995-2009 & 25 & 72 & $N R$ & 73.9 & 42.8 & 36.7 & 33.4 \\
\hline Morise et al. (50) & 2008 & Japan & Retro & 1989-2004 & 18 & 64 & NR & 56.3 & 27.3 & 27.3 & 13 \\
\hline Nishi et al. (51) & 2018 & Japan & Retro & 1996-2008 & 39 & 64 & 0 & 56.4 & 17.9 & 10.3 & 14 \\
\hline Nomura et al. (52) & 2009 & Japan & Retro & 1991-2005 & 17 & 65.8 & NR & $N R$ & $N R$ & 30.8 & 21 \\
\hline Ohkura et al. (53) & 2015 & Japan & Retro & 1985-2014 & 9 & 66 & NR & 88.9 & 29.6 & $\mathrm{NR}$ & NR \\
\hline Okano et al. (54) & 2002 & Japan & Retro & 1986-1999 & 19 & 69 & $\mathrm{NR}$ & 77 & 34 & 34 & 21 \\
\hline Oki et al. (55) & 2016 & Japan & Retro & 2000-2010 & 94 & 70 & NR & 86.5 & 51.4 & 42.1 & 40.8 \\
\hline Qiu et al. (56) & 2013 & China & Retro & 1998-2009 & 25 & $N R$ & 0 & 96 & 70.4 & 29.4 & 38 \\
\hline Roh et al. (et al. (57) & 2005 & Korea & Retro & 1988-1996 & 11 & 61 & 0 & 73 & NR & 27 & 19 \\
\hline Rudloff et al. (58) & 2014 & USA & Pro & 2009-2012 & 9 & 45 & NR & 44.4 & 33.3 & 22.2 & 11.3 \\
\hline Ryu et al. (59) & 2017 & Japan & Retro & 1997-2015 & 14 & NR & NR & 84.6 & 51.3 & 51.3 & NR \\
\hline Saiura et al. (60) & 2002 & Japan & Retro & 1981-1998 & 10 & 60.5 & 30 & 50 & 30 & 20 & 25 \\
\hline Sakamoto et al. (61) & 2007 & Japan & Retro & 1990-2005 & 37 & 64 & 0 & NR & NR & 11 & 31 \\
\hline Schildberg et al. (62) & 2012 & Germany & Retro & 1972-2008 & 31 & 65 & 6 & $N R$ & $N R$ & 13 & NR \\
\hline Shinohara et al. (63) & 2015 & Japan & Retro & 1995-2010 & 22 & $N R$ & 0 & 86 & 26 & 26 & 22 \\
\hline Shirabe et al. (64) & 2003 & Japan & Retro & 1979-2001 & 36 & 66 & 0 & 64 & 26 & 26 & $N R$ \\
\hline Song et al. (65) & 2017 & China & Retro & 2001-2012 & 96 & 63 & 0 & 87.5 & 47.6 & 21.7 & 34 \\
\hline Takemura et al. (66) & 2012 & Japan & Retro & 1993-2011 & 64 & 65 & 0 & 84 & 50 & 37 & 34 \\
\hline Thelen et al. (5) & 2008 & Germany & Retro & 1988-2002 & 24 & 64 & 4.2 & 38 & 16 & 10 & 9 \\
\hline Tiberio et al. (67) & 2016 & Italy & Retro & 1990-2013 & 105 & 68 & 0.9 & 58.2 & 20.3 & 13.1 & 14.6 \\
\hline Tsujimoto et al. (68) & 2010 & Japan & Retro & 1980-2007 & 17 & 66 & NR & 75 & 37.5 & 31.5 & 34 \\
\hline Turanli et al. (21) & 2010 & Turkey & Pro & 2005-2008 & 18 & $N R$ & NR & $N R$ & 0 & 0 & 14.1 \\
\hline Ueda et al. (69) & 2009 & Japan & Retro & 1991-2005 & 15 & NR & 0 & 80 & NR & 60 & 13.4 \\
\hline Viganò et al. (70) & 2013 & Italy & Retro & 1997-2008 & 20 & 61.5 & 0 & 95 & 63.2 & 33.2 & 52.3 \\
\hline Wang et al. (71) & 2012 & China & Retro & 2003-2008 & 30 & 60 & 0 & 43.3 & 16.7 & 16.7 & 11 \\
\hline Wang et al. (72) & 2014 & China & Retro & 1996-2008 & 39 & 64 & 0 & 56 & 17.9 & 10.3 & 14 \\
\hline Zacherl et al. (73) & 2002 & Austria & Retro & 1980-1999 & 15 & 62 & 0 & 36 & 14.3 & 0 & 8.8 \\
\hline
\end{tabular}

Retro indicates retrospective study; NR, not reported; MST, median survival time. 
selected patients (48). Kaplan-Meier curve analyses showed that patients who were selected to have gastrectomy with additional hepatectomy for liver metastases (GGH group) had survival similar to that of patients who had gastrectomy in the absence of liver metastases (GG group) $(P=0.196)$ and improved survival than did patients who had gastrectomy without liver resection for liver metastases (GGNH group) $(P<0.001)$ and patients with GCLM who had no surgery (GNS group) $(P<0.001)$. As for mortality, the GGH group and GGNH group had similar 30day mortality $(P=0.246)$, whereas the former had significantly improved 90 -day mortality $(P=0.009)$, 1 -year mortality $(P<$ $0.001)$, and 5-year mortality $(P<0.001)$; and the GNS group had the worst $O S$ and highest mortality at 30, 90 days, 1 , and 5 years $(P$ $<0.001)$ in the four groups. The results of this study revealed that gastrectomy combined with additional surgical resection of liver metastases was better than palliative treatment or gastrectomy without resection of liver metastases for patients with GCLM in survival benefits.

To reassess this bias problem in full measure, many systematic reviews and pooled analyses were conducted. A systematic review launched by Liao et al. (74) included eight non-randomized studies, representing a total of 677 patients with GCLM. The median OS time in patients who underwent gastrectomy combined with hepatectomy was significantly prolonged, as compared with the median OS time of those who underwent palliative therapy (23.7 vs. 7.6 months), with survival rates of the two arms of $69,40,33 \%$, and $27,8,4 \%$ at 1,2 , and 3 years, respectively. Compared with palliative therapy, hepatectomy was associated with significantly lower mortality at 1 -year (OR 0.17 , $P<0.001$ ) and 2-year (OR 0.15, $P<0.001$ ). Owing to the disparity in the stage of disease, differences of the regimen of chemotherapy, and preference of surgery of surgeons (75), patients who underwent hepatectomy in Western countries showed lower median rates of OS at 1 year (60 vs. $76 \%), 2$ years ( 30 vs. $47 \%$ ), and 3 years ( 23 vs. $39 \%$ ) than did those in Asian countries.

As previously stated, most of the published papers on surgical resection in patients with GCLM came from retrospective data, whereas only four randomized controlled trials (RCTs) investigated the role of surgery for patients with GCLM so far. The REGATTA trial was the first RCT to compare gastrectomy followed by chemotherapy with chemotherapy alone concerning OS in patients with GCLM (22). Findings from this trial denied the survival efficacy of palliative gastrectomy followed by chemotherapy from an interim analysis, which had caused the interruption of this trial in 2016. However, to some extent, results from the AIO-FLOT3 trial countered those of the REGATTA trial by strict inclusion criteria, surgical approaches, and treatment regimens (23). The AIO-FLOT3 trial exhibited favorable survival in patients with GCLM who received neoadjuvant chemotherapy and later underwent surgical resection, which had provided a rationale for the ongoing AIO-FLOT5 trial (NCT02578368) (76). Compared with the REGATTA trial, the AIO-FLOT5 trial excludes the enrollment of patients with clinically visible tumors of the peritoneum and $>\mathrm{P} 1$ peritoneal tumors, adopts a complete resection of a primary tumor including standardized lymphadenectomy (R0 and at least D2), and adjusts the place of chemotherapy and surgery. Hopefully, if this trial was proved to be effective, it could potentially lead to a new standard of therapy. Another ongoing trial named SURGIGAST (NCT03042169), which has not recruited patients, aims to compare the OS of palliative surgical resection plus chemotherapy with that of chemotherapy alone for stage IV gastric cancer including GCLM (77).

Despite the significant survival benefits from gastrectomy combined with hepatectomy over non-resectional management in patients with GCLM, as well as favorable published outcomes from chemotherapy followed by surgery over chemotherapy alone, it must be stressed that most of data came from retrospective studies and systematic reviews. Thus, outcome data from the AIO-FLOT5 trial and the SURGIGAST trial are awaited to verify the survival benefit of surgical resection suggested by retrospective studies and systematic reviews.

\section{Prognostic Factors and Patient Selection in Gastric Cancer With Liver Metastasis}

A considerable amount of published literature about surgery in GCLM illustrates the ascendency of surgery. However, it is conspicuous that not every patient will benefit from surgery. Hence, prognostic evaluation is crucial to identify the suitable candidates for radical surgery, which are of gastric cancer, liver metastases (synchronous disease), and liver metastases alone (metachronous disease), from those who will not benefit from surgery.

Lately, in a multicenter retrospective study, Tiberio et al. (78) compared the application of radical surgery vs. palliative gastrectomy or palliative surgery without resection in GCLM, in which radical surgery had achieved better long-term results than others in the 5-year survival rate $(9.3,2.1$, and $0 \%$, respectively). In light of this, they further recognized the best candidates for radical surgery through systematically investigating the patientrelated, gastric cancer-related, metastasis-related, and treatmentrelated prognostic factors. Results confirmed that the invasive depth of primary tumor $(P<0.001)$, curative surgical procedure (R0 resection; $P=0.001$ ), timing of hepatic involvement $(P<0.001)$, and adjuvant chemotherapy $(P<0.001)$ were associated with long-term survival, independently. Especially in $\mathrm{R} 0$ resection, results implied that it can significantly reduce the possibility of recurrence in GC patients with liver oligometastasis, even in patients with multiply scattered metastases in both lobes of the liver.

Accordingly, in the metachronous disease, Tiberio et al. (79) also revealed that T4 gastric cancer $(P=0.019)$, the presence of lymph node metastases $(P=0.05)$, and grade $3 \mathrm{GC}$ $(P=0.018)$ displayed negative prognostic factors. Moreover, a multivariate analysis demonstrated that a therapeutic strategy of liver metastases was highly associated with survival as well, in particular when R0 resection was performed $(P<0.001)$.

Likewise, based on real-world data, the AGAMENON registry involving 1,792 patients with advanced GC (80), distal esophagus, or gastroesophageal junction revealed higher 3-year survival rate after metastasectomy than non-metastasectomy (30.6 vs. $8.4 \%$; $P$ $<0.001$ ) and median OS since metastasectomy of 16.7 months. 
With the use of a state-arrival extended Markov proportional hazard $(\mathrm{PH})$ model, a multivariate analysis indicated the presence of a HER2-positive tumor treated with trastuzumab $(P=0.001)$ and chemotherapy followed by surgical procedure $(P<0.001)$ as favorable predictors of survival. Moreover, they also found that the unreasonable interval time between the initiation of chemotherapy and surgery appeared to worsen outcomes. Their results also recommended that 5 months as interval time benefits most patients, which is consistent with the AIO-FLOT3 trial.

Also, Takemura et al. (66) reported the overall 5-year survival rate of $37 \%$ and the MST of 34 months in 64 patients achieved macroscopically complete (R0 or R1) resections. Among 64 patients, 50 patients had the largest hepatic metastasis of more than $5 \mathrm{~cm}$ in diameter, and 14 patients had $<5 \mathrm{~cm}$ in diameter $(P=0.07)$. Results demonstrated that patients with a maximum diameter of hepatic metastasis $>5 \mathrm{~cm}$ had poorer long-term survival $(P=0.018)$.

Above all, most of identified prognostic factors were similar with those in various literature through multivariate analyses, which could be roughly divided into five major categories that consisted of primary tumor-associated, liver metastasisassociated, extrahepatic metastasis-associated, and treatmentassociated prognostic factors and others, as shown in Table 2. However, these factors were mainly identified from retrospective studies in single center or multicenter, which need to be validated in prospective clinical studies to further confirm their prognostic role.

\section{SURGERY IN DIFFERENT CATEGORIES OF GASTRIC CANCER WITH LIVER METASTASIS}

\section{New Classified Evaluation for Gastric Cancer With Liver Metastasis}

Although the Lauren classification and the WHO classification are popular in pathological grading of GCs, they are insufficient to guide personalized treatments, especially in GCLM. New classified evaluation for GCLM is thus required. Encouragingly, recent advancements in retrospective studies and prospective studies have greatly facilitated the identification of potential candidates.

Referring to the clinical study on GCLM and classification of stage IV GC (83), we divided GCLM patients into three categories, as shown in Figure 1. First, GCLM could be divided into the potentially resectable tumor (category I), marginally resectable tumor (category II), and unresectable tumor (category III) according to the analysis of clinical decision making in multidisciplinary treatment. For example, macroscopic peritoneal dissemination was considered an essential factor during the classification process, because patients with peritoneal dissemination or positive peritoneal cytology had significantly poor prognosis (84). Second, patients of category I were recommended to undergo surgery followed by post-operative chemotherapy or to receive neoadjuvant chemotherapy combined with surgery. Patients in category II were suggested to adopt conversion therapy aimed to an $\mathrm{R} 0$ resection after combined chemotherapy. Patients in category III, who also had obstruction and bleeding of the gastrointestinal tract in some cases, were advised to receive palliative chemotherapy.

\section{Surgery Strategies in Different Categories of Gastric Cancer With Liver Metastasis} Surgery in Resectable Liver Metastases (Category I)

Potentially resectable liver metastases (category I) were characterized by $<5$ metastasis (better for solitary metastasis), with the diameter of the largest metastatic lesion measuring $<5 \mathrm{~cm}$ and metastasis occurring in one liver lobe, which was regarded as a technically resectable metastasis.

For patients who conformed to the defining characteristics of category I, evidence from clinical trials and retrospective studies recommended them to undergo neoadjuvant chemotherapy followed by R0 resection of hepatic metastasis with or without primary GC and D2 lymphadenectomy and postoperative chemotherapy. Komeda et al. (43) indicated that the overall 5-year survival rate and MST of patients with GCLM who underwent gastrectomy followed by curative hepatectomy were $40.1 \%$ and 22.3 months, respectively. Especially in patients with a maximum size of liver metastasis $\leq 5 \mathrm{~cm}$, they had higher overall 5-year survival than had patients with a maximum size of liver metastasis $>5 \mathrm{~cm}$ (51.7 vs. $14.3 \%)$. Furthermore, in a retrospective study that enrolled 24 patients with GC with two or three liver-limited metastases, Shirasu et al. (81) found no survival benefit for patients who experienced hepatectomy only compared with chemotherapy only $(P=0.146)$. However, recurrence and death occurred in none of the patients who received initial chemotherapy followed by surgery. Despite small sample size of patients, this study still should be regarded as a direction for further study.

Similarly, in a prospectively comparative study involving 49 patients with synchronous GCLM, Li et al. (6) compared patients assigned to R0 resection of primary tumor and liver metastasis as well as D2 lymphadenectomy followed by postoperative chemotherapy with patients assigned to chemotherapy only. Results revealed that the MST of surgery group was significantly longer than that of the control group (20.5 vs. 9.1 months). Moreover, the response to chemotherapy was indicated by the prognostic factors only through their multivariate analysis. Remarkably, the AIO-FLOT3 trial (23) enrolled 60 patients with liver metastases of $<5$ to receive eight cycles of the FOLT (fluorouracil, oxaliplatin, leucovorin, and docetaxel) chemotherapy in total, 36 of whom underwent surgery to achieve margin-free (R0) resection after the first four cycles of neoadjuvant chemotherapy. Compared with 24 patients assigned to chemotherapy only, 36 patients with surgery had more favorable MST (31.3 vs. 15.9 months) and progression-free survival (26.7 vs. 8.4 months).

In this case, initial gastrectomy and hepatectomy aimed to achieve R0 resection; otherwise, it should combined with neoadjuvant chemotherapy. Indeed, R0 resection was a microscopically margin-negative resection, in which no gross or microscopic tumor was kept in the primary tumor site, 
TABLE 2 | Independent favorable prognostic factors for surgery in patients with GCLM.

\begin{tabular}{|c|c|c|}
\hline Categories & Favorable prognostic factors & References \\
\hline \multirow[t]{3}{*}{ Primary tumor } & No serosal invasion & $(40,66)$ \\
\hline & Lower T stage & $(33,49,65,67,78,79)$ \\
\hline & No lymphatic or venous invasion & $(46,55,72,79)$ \\
\hline \multirow[t]{4}{*}{ Liver metastases } & Unilobar involvement & $(26,47,61,73,78,81)$ \\
\hline & Number of metastatic lesions $\leq 3$, especially for solitary metastasis & $(30,35,40,41,46,52-56,61-63,65,69-72)$ \\
\hline & Diameter of greatest lesion $\leq 5 \mathrm{~cm}$ & $(36,40,43,53,66,68)$ \\
\hline & Metachronous metastases & $(27,51,54,62,67)$ \\
\hline Extrahepatic metastasis & Absence of peritoneal metastasis & $(38,39,44,69,71)$ \\
\hline \multirow[t]{5}{*}{ Treatment } & Negative margin (RO) & $(5,21,30,35,62,67,69,82)$ \\
\hline & D2 Lymphadenectomy & (68) \\
\hline & Neoadjuvant chemotherapy & (23) \\
\hline & Post-operative chemotherapy & $(42,56,67,78)$ \\
\hline & Response to chemotherapy & $(6,70)$ \\
\hline \multirow[t]{2}{*}{ Other } & Lower CEA and CA 19-9 levels & $(33,59)$ \\
\hline & HER2-positive tumor treated with trastuzumab & $(23,80)$ \\
\hline
\end{tabular}

GCLM, gastric cancer with liver metastases; CEA, carcinoembryonic antigen; CA 19-9, carbohydrate antigen 19-9.

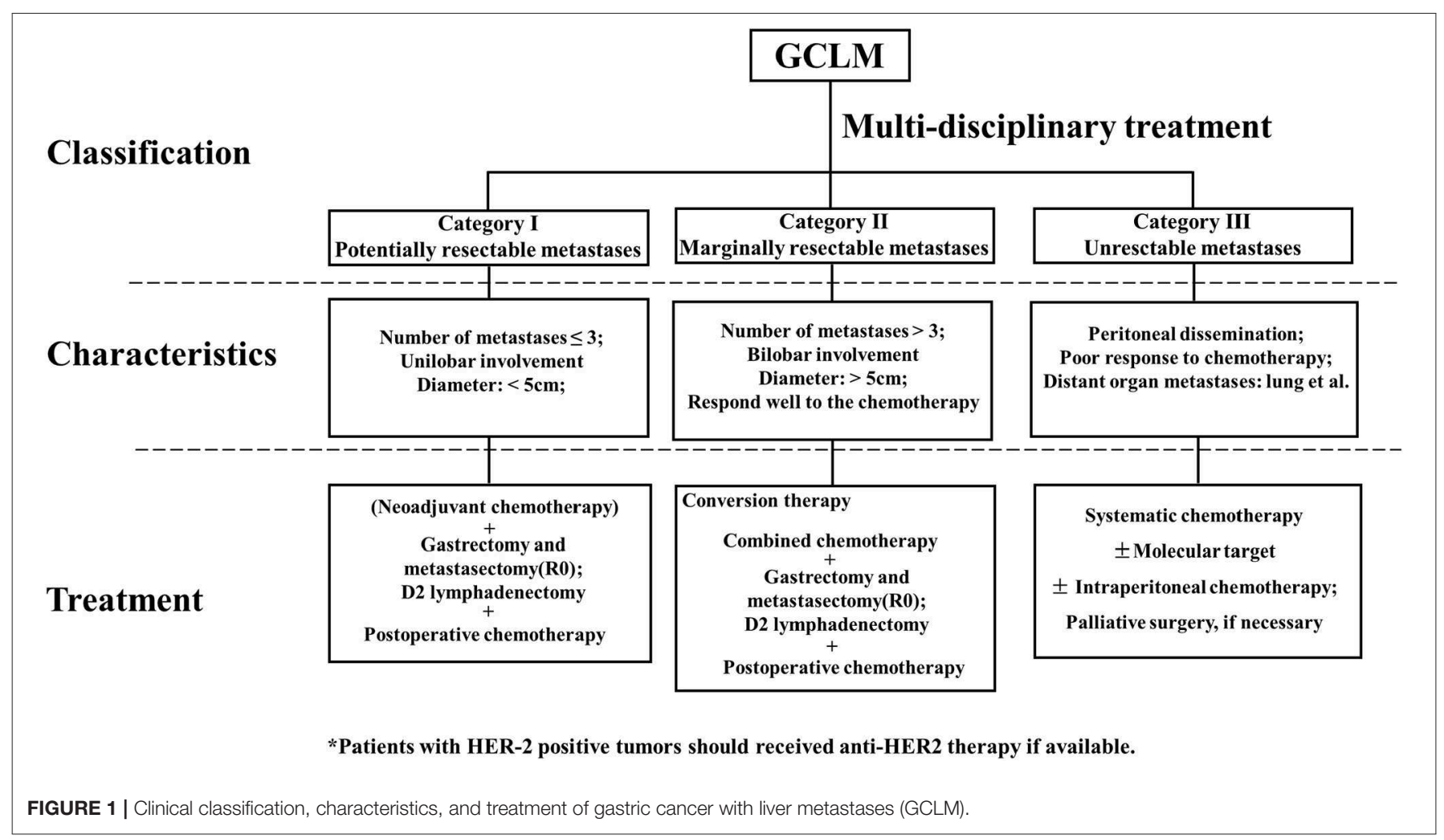

which could remove the tumor and retain tissues to the hilt. Simultaneously, neoadjuvant chemotherapy was able to treat micrometastases at an early stage to downstage the primary tumor and obtained a higher $\mathrm{R} 0$ resection rate. Moreover, postoperative chemotherapy acted as a "supervisor" to maintain the state of R0 resection, for prevention of progression and recurrence of metastasis of gastric cancer. Thus, patients in this category were highly inclined to achieve R0 resection and obtain reduced recurrence rate.

\section{Surgery in Marginally Resectable Liver Metastases (Category II)}

Marginally resectable liver metastases (category II) was composed of patients with multiple liver metastases $(>3)$, maximum tumor diameter that exceeds $5 \mathrm{~cm}$, or bilobar invasion with the absence of peritoneal metastases. This category was regarded as oncologically and technically unresectable.

In clinical practice, surgery is controversial for these patients, as they are usually offered chemotherapy. However, existing 
evidence indicated that initially marginally resectable and unresectable gastric cancer could be converted into resectable gastric cancer by novel combined chemotherapy (83-85). Thus, recent studies begin to focus on surgery with an expectation of $\mathrm{R} 0$ resection performed in originally unresectable and marginally resectable GCLM that responded to chemotherapy. Fukuchi et al. (84) selected S-1 plus cisplatin or paclitaxel as initial combination chemotherapy for advanced gastric cancer including GCLM. Compared with patients who only received chemotherapy, patients treated with chemotherapy plus surgery had a prolonged survival at 5 years ( 43 vs. $1 \%$ ).

Moreover, among patients who underwent conversion therapy, patients who underwent R0 resection had significantly more favorable survival as opposed to those who underwent $\mathrm{R}+$ resections ( 49 vs. $15 \%$ in a 5 -year survival rate). In a recent retrospective study involving patients with marginally resectable tumor, Yamaguchi et al. (82) reported that the MST of patients assigned to conversion therapy was 30.5 months, whereas that of patients assigned chemotherapy alone was 11.0 months $(P$ $<0.05)$. In a group of conversion therapy, patients underwent $\mathrm{R} 0$ resection had prolonged survival time than had those who underwent $\mathrm{R}+$ resection (56.2 vs. 16.3 months).

In spite of the encouraging outcomes mentioned, the limitations of the above studies should be noted. First, enrolled patients for most studies have experienced for a long period lack of consistencies in the decision making of diagnosis and in approaches of chemotherapeutic regimen and surgery. Second, inherent selection bias occurred in retrospective data including response to chemotherapy and performance status, which could affect outcomes. Third, in almost all retrospective studies, owing to the insufficiency in evidence of clinical characteristics including laboratory data and molecular classification, clinicopathological factors and response to chemotherapy were considered as major factors to predict the candidates for potential R0 surgical resection. Consequently, existing studies should accelerate the implementation of randomized clinical trials to determine the role of conversion therapy and to explore the effect of laboratory data and molecular classification on survival benefit to provide a guideline for patient stratification and personalized treatment in GCLM (86).

\section{Surgery in Unresectable Liver Metastases (Category III)}

Unresectable liver metastases (category III) contained patients with macroscopically peritoneal dissemination or extensive metastases in multiple organs, who carry a worse or less favorable prognosis.

According to recent studies, patients in category III could benefit from conversion therapy as well. However, only a small fraction of patients who responded well to chemotherapy were accessible to achieve R0 resection (87). Moreover, palliative chemotherapy remained as a mainstream treatment according to clinical guidelines. Consistent with palliative radiotherapy (88), palliative surgery also plays a vital role in coping with obstruction and bleeding of the gastrointestinal tract.

Above all, because most evidence came from retrospective studies, defining the role of surgery in different categories of GCLM was in need of more robust evidence from prospective randomized clinical trials. Furthermore, a combination of clinical classification and molecular classification of GCLM might accelerate the identification of novel therapeutic targets and formation of personalized treatment $(89,90)$.

\section{PERSPECTIVES}

In summary, despite the increasing evidence in favor of surgery in GCLM, the indication and extent of surgery, including the selection of patients and the potential to achieve R0 resection, should be carefully discussed and determined. Emerging research indicated that hepatic arterial infusion chemotherapy (HAIC), radiation therapy, and radiofrequency ablation (RFA) provided alternative treatment modalities for $\operatorname{GCLM}(36,91,92)$. Importantly, prospective randomized clinical trials are needed urgently to clarify the indication and the surgery strategies in GCLM.

\section{AUTHOR CONTRIBUTIONS}

$\mathrm{ZL}$ and $\mathrm{CH}$ were involved in the concept and design. ZL, ZR, and $\mathrm{CH}$ wrote, reviewed, and revised the manuscript. $\mathrm{CH}$ supervised the manuscript.

\section{FUNDING}

This study was financially supported by National Natural Science Foundation of China (817725276), Shanghai Municipal Education Commission-Gaofeng Clinical Medicine Grant Support (20161425), Shanghai Jiao Tong University Medical cross fund (YG2017MS28), and Science and Technology Commission Project of Songjiang District (18sjkjgg23).

\section{REFERENCES}

1. Bray F, Ferlay J, Soerjomataram I, Siegel RL, Torre LA, Jemal A. Global cancer statistics 2018: GLOBOCAN estimates of incidence and mortality worldwide for 36 cancers in 185 countries. Cancer J Clin. (2018) 68:394-424. doi: $10.3322 /$ caac. 21492

2. Chen W, Zheng R, Baade PD, Zhang S, Zeng H, Bray F, et al. Cancer statistics in China, 2015. Cancer J Clin. (2016) 66:115-32. doi: 10.3322/caac. 21338

3. Howlader N, Noone AM, Krapcho M, Garshell J, Neyman N, Altekruse SF, et al. SEER Cancer Statistics Review, 1975-2010. Bethesda, MD: National Cancer Institute (2013). Available online at: https://seer.cancer.gov/archive/csr/1975_2010/

4. Shin A, Kim J, Park S. Gastric cancer epidemiology in Korea. J Gastr Cancer. (2011) 11:135-40. doi: 10.5230/jgc.2011.11.3.135

5. Thelen A, Jonas S, Benckert C, Lopez-Hanninen E, Neumann U, Rudolph B, et al. Liver resection for metastatic gastric cancer. Eur J Surg Oncol. (2008) 34:1328-34. doi: 10.1016/j.ejso.2008.01.022 
6. Li Z, Fan B, Shan F, Tang L, Bu Z, Wu A, et al. Gastrectomy in comprehensive treatment of advanced gastric cancer with synchronous liver metastasis: a prospectively comparative study. World J Surg Oncol. (2015) 13:212. doi: 10.1186/s12957-015-0627-1

7. D'Angelica M, Gonen M, Brennan MF, Turnbull AD, Bains M, Karpeh MS. Patterns of initial recurrence in completely resected gastric adenocarcinoma. Ann Surg. (2004) 240:808-16. doi: 10.1097/01.sla.0000143245.28656.15

8. National Comprehensive Cancer Network (NCCN). Clinical Practice Guidelines in Oncology. Gastric Cancer, Version 5. (2017). Available online at: https://www.nccn.org/professionals/physician_gls/f_guidelines.asp (accessed September 15, 2016).

9. Koizumi W, Narahara H, Hara T, Takagane A, Akiya T, Takagi M, et al. S1 plus cisplatin versus S-1 alone for first-line treatment of advanced gastric cancer (SPIRITS trial): a phase III trial. Lancet Oncol. (2008) 9:215-21. doi: 10.1016/S1470-2045(08)70035-4

10. Yamada Y, Higuchi K, Nishikawa K, Gotoh M, Fuse N, Sugimoto N, et al. Phase III study comparing oxaliplatin plus S-1 with cisplatin plus S-1 in chemotherapy-naïve patients with advanced gastric cancer. Ann Oncol. (2015) 26:141-8. doi: 10.1093/annonc/mdu472

11. Bang YJ, Van Cutsem E, Feyereislova A, Chung HC, Shen L, Sawaki A, et al. Trastuzumab in combination with chemotherapy versus chemotherapy alone for treatment of HER2-positive advanced gastric or gastro-oesophageal junction cancer (ToGA): a phase 3, open-label, randomised controlled trial. Lancet. (2010) 376:687-97. doi: 10.1016/S0140-6736(10)61121-X

12. Kang YK, Boku N, Satoh T, Ryu MH, Chao Y, Kato K, et al. Nivolumab in patients with advanced gastric or gastro-oesophageal junction cancer refractory to, or intolerant of, at least two previous chemotherapy regimens (ONO-4538-12, ATTRACTION-2): a randomised, double-blind, placebo-controlled, phase 3 trial. Lancet. (2017) 390:2461-71. doi: 10.1016/S0140-6736(17)31827-5

13. de Hosson LD, van Veenendaal LM, Schuller Y, Zandee WT, de Herder WW, Tesselaar MET, et al. Clinical benefit of systemic treatment in patients with advanced pancreatic and gastrointestinal neuroendocrine tumours according to ESMO-MCBS and ASCO framework. Ann Oncol. (2017) 28:3022-27. doi: 10.1093/annonc/mdx547

14. Shah MA. Update on metastatic gastric and esophageal cancers. J Clin Oncol. (2015) 33:1760-9. doi: 10.1200/JCO.2014.60.1799

15. Quan D, Gallinger S, Nhan C, Auer RA, Biagi JJ, Fletcher GG, et al. The role of liver resection for colorectal cancer metastases in an era of multimodality treatment: a systematic review. Surgery. (2012) 151:860-70. doi: 10.1016/j.surg.2011.12.018

16. Hur H, Ko YT, Min BS, Kim KS, Choi JS, Sohn SK, et al. Comparative study of resection and radiofrequency ablation in the treatment of solitary colorectal liver metastases. Am J Surg. (2009) 197:728-36. doi: 10.1016/j.amjsurg.2008.04.013

17. Markar SR, Mikhail S, Malietzis G, Athanasiou T, Mariette C, Sasako $\mathrm{M}$, et al. Influence of surgical resection of hepatic metastases from gastric adenocarcinoma on long-term survival: systematic review and pooled analysis. Ann Surg. (2016) 263:1092-101. doi: 10.1097/SLA.0000000000001542

18. Oguro S, Imamura H, Yoshimoto J, Ishizaki Y, Kawasaki S. Liver metastases from gastric cancer represent systemic disease in comparison with those from colorectal cancer. J Hepato Biliary Pancr Sci. (2016) 23:324-32. doi: $10.1002 /$ jhbp. 343

19. Kodera Y, Fujitani K, Fukushima N, Ito S, Muro K, Ohashi N, et al. Surgical resection of hepatic metastasis from gastric cancer: a review and new recommendation in the Japanese gastric cancer treatment guidelines. Gastr Cancer. (2014) 17:206-12. doi: 10.1007/s10120-013-0299-x

20. Lee JW, Choi MH, Lee YJ, Ali B, Yoo HM, Song KY, et al. Radiofrequency ablation for liver metastases in patients with gastric cancer as an alternative to hepatic resection. BMC Cancer. (2017) 17:185. doi: 10.1186/s12885-017-3156-1

21. Turanli S. The value of resection of primary tumor in gastric cancer patients with liver metastasis. Ind J Surg. (2010) 72:200-5. doi: 10.1007/s12262-010-0053-0

22. Fujitani K, Yang HK, Mizusawa J, Kim YW, Terashima M, Han SU, et al. Gastrectomy plus chemotherapy versus chemotherapy alone for advanced gastric cancer with a single non-curable factor (REGATTA): a phase 3, randomised controlled trial. Lancet Oncol. (2016) 17:309-18. doi: 10.1016/S1470-2045(15)00553-7

23. Al-Batran SE, Homann N, Pauligk C, Illerhaus G, Martens UM, Stoehlmacher J, et al. Effect of neoadjuvant chemotherapy followed by surgical resection on survival in patients with limited metastatic gastric or gastroesophageal junction cancer: the AIO-FLOT3 Trial. JAMA Oncol. (2017) 3:1237-44. doi: 10.1001/jamaoncol.2017.0515

24. Hu Y, Huang C, Sun Y, Su X, Cao H, Hu J, et al. Morbidity and mortality of laparoscopic versus open D2 distal gastrectomy for advanced gastric cancer: a randomized controlled trial. J Clin Oncol. (2016) 34:1350-7. doi: 10.1200/JCO.2015.63.7215

25. Adam R, Chiche L, Aloia T, Elias D, Salmon R, Rivoire M, et al. Hepatic resection fornoncolorectal nonendocrine liver metastases: analysis of 1,452 patients and development of a prognostic model. Ann Surg. (2006) 244:52435. doi: 10.1097/01.sla.0000239036.46827.5f

26. Aizawa M, Nashimoto A, Yabusaki H, Nakagawa S, Matsuki A. Clinical benefit of surgical management for gastric cancer with synchronous liver metastasis. Hepatogastroenterology. (2014) 61:1439-45. doi: 10.5754/hge14149

27. Ambiru S, Miyazaki M, Ito H, Nakagawa K, Shimizu H, Yoshidome H, et al. Benefits and limits of hepatic resection for gastric metastases. Am J Surg. (2001) 181:279-83. doi: 10.1016/S0002-9610(01)00567-0

28. Baek HU, Kim SB, Cho EH, Jin SH, Yu HJ, Lee JI, et al. Hepatic resection for hepatic metastases from gastric adenocarcinoma. J Gastr Cancer. (2013) 13:86-92. doi: 10.5230/jgc.2013.13.2.86

29. Chen L, Song MQ, Lin HZ, Hao LH, Jiang XJ, Li ZY, et al. Chemotherapy and resection for gastric cancer with synchronous liver metastases. World J Gastroenterol. (2013) 19:2097-103. doi: 10.3748/wjg.v19.i13.2097

30. Cheon SH, Rha SY, Jeung HC, Im CK, Kim SH, Kim HR, et al. Survival benefit of combined curative resection of the stomach (D2 resection) and liver in gastric cancer patients with liver metastases. Ann Oncol. (2008) 19:1146-53. doi: 10.1093/annonc/mdn026

31. Choi SB, Song J, Kang CM, Hyung WJ, Kim KS, Choi JS, et al. Surgical outcome of metachronous hepatic metastases secondary to gastric cancer. Hepatogastroenterology. (2010) 57:29-34.

32. Dittmar Y, Altendorf-Hofmann A, Rauchfuss F, Götz M, Scheuerlein H, Jandt $\mathrm{K}$, et al. Resection of liver metastases is beneficial in patients with gastric cancer: report on 15 cases and review of literature. Gastr Cancer. (2012) 15:131-6. doi: 10.1007/s10120-011-0080-y

33. Fukami Y, Kaneoka Y, Maeda A, Takayama Y, Takahashi T, Uji M, et al. Adjuvant hepatic artery infusion chemotherapy after hemihepatectomy for gastric cancer liver metastases. Int J Surg. (2017) 46:79-84. doi: 10.1016/j.ijsu.2017.08.578

34. Fujii K, Fujioka S, Kato K, Machiki Y, Kutsuna Y, Ishikawa A, et al. Resection of liver metastasis from gastric adenocarcinoma. Hepatogastroenterology. (2001) 48:368-71.

35. Garancini M, Uggeri F, Degrate L, Nespoli L, Gianotti L, Nespoli A, et al. Surgical treatment of liver metastases of gastric cancer: is local treatment in a systemic disease worthwhile? HPB. (2012) 14:209-15. doi: 10.1111/j.1477-2574.2011.00428.x

36. Guner A, Son T, Cho I, Kwon IG, An JY, Kim HI, et al. Liver-directed treatments for liver metastasis from gastric adenocarcinoma: comparison between liver resection and radiofrequency ablation. Gastr Cancer. (2016) 19:951-60. doi: 10.1007/s10120-015-0522-z

37. Hirai I, Kimura W, Fuse A, Isobe H, Hachiya O, Moriya $T$, et al. Surgical management for metastatic liver tumors. Hepatogastroenterology. (2006) 53:757-63.

38. Hwang SE, Yang DH, Kim CY. Prognostic factors for survival in patients with hepatic recurrence after curative resection of gastric cancer. World J Surg. (2009) 33:1468-72. doi: 10.1007/s00268-0090034-2

39. Imamura H, Matsuyama $\mathrm{Y}$, Shimada $\mathrm{R}$, Kubota $\mathrm{M}$, Nakayama A, Kobayashi A, et al. A study of factors influencing prognosis after resection of hepatic metastases from colorectal and gastric carcinoma. Am J Gastroenterol. (2001) 96:3178-84. doi: 10.1111/j.1572-0241.2001.0 5278.x

40. Kinoshita T, Kinoshita T, Saiura A, Esaki M, Sakamoto H, Yamanaka T. Multicentre analysis of long-term outcome after surgical resection for gastric cancer liver metastases. Br J Surg. (2015) 102:102-7. doi: 10.1002/bjs.9684 
41. Koga R, Yamamoto J, Ohyama S, Saiura A, Seki M, Seto Y, et al. Liver resection for metastatic gastric cancer: experience with 42 patients including eight longterm survivors. Jap J Clin Oncol. (2007) 37:836-42. doi: 10.1093/jjco/hym113

42. Kokkola A, Louhimo J, Puolakkainen P. Does non-curative gastrectomy improve survival in patients with metastatic gastric cancer? J Surg Oncol. (2012) 106:193-6. doi: 10.1002/jso.23066

43. Komeda K, Hayashi M, Kubo S, Nagano H, Nakai T, Kaibori M, et al. High survival in patients operated for small isolated liver metastases from gastric cancer: a multi-institutional study. World J Surg. (2014) 38:2692-7. doi: $10.1007 / \mathrm{s} 00268-014-2608-\mathrm{x}$

44. Li SC, Lee CH, Hung CL, Wu JC, Chen JH. Surgical resection of metachronous hepatic metastases from gastric cancer improves longterm survival: a population-based study. PLoS ONE. (2017) 12:e0182255. doi: 10.1371/journal.pone. 0182255

45. Liu J, Li JH, Zhai RJ, Wei B, Shao MZ, Chen L. Predictive factors improving survival after gastric and hepatic surgical treatment in gastric cancer patients with synchronous liver metastases. Chin Med J. (2012) 125:165-71. doi: 10.3760/cma.j.issn.0366-6999.2012.02.001

46. Liu Q, Bi JJ, Tian YT, Feng Q, Zheng ZX, Wang Z. Outcome after simultaneous resection of gastric primary tumour and synchronous liver metastases: survival analysis of a single-center experience in China. Asian Pac J Cancer Prev. (2015) 16:1665-9. doi: 10.7314/APJCP.2015.16.4.1665

47. Makino H, Kunisaki C, Izumisawa $Y$, Tokuhisa M, Oshima T, Nagano $Y$, et al. Indication for hepatic resection in the treatment of liver metastasis from gastric cancer. Anticancer Res. (2010) 30:2367-76. Available online at: http:// ar.iiarjournals.org/content/30/6/2367.long

48. Markar SR, Mackenzie H, Mikhail S, Mughal M, Preston SR, Maynard $\mathrm{ND}$, et al. Surgical resection of hepatic metastases from gastric cancer: outcomes from national series in England. Gastr Cancer. (2017) 20:379-86. doi: 10.1007/s10120-016-0604-6

49. Miki Y, Fujitani K, Hirao M, Kurokawa Y, Mano M, Tsujie M, et al. Significance of surgical treatment of liver metastases from gastric cancer. Anticancer Res. (2012) 32:665-70. Available online at: http://ar.iiarjournals.org/content/32/2/ 665.long

50. Morise Z, Sugioka A, Hoshimoto S, Kato T, Ikeda M, Uyama I, et al. The role of hepatectomy for patients with liver metastases of gastric cancer. Hepatogastroenterology. (2008) 55:1238-41.

51. Nishi M, Shimada M, Yoshikawa K, Higashijima J, Tokunaga T, Kashihara H, et al. Results of hepatic resection for liver metastasis of gastric cancer. J Med Invest. (2018) 65:27-31. doi: 10.2152/jmi.65.27

52. Nomura T, Kamio Y, Takasu N, Moriya T, Takeshita A, Mizutani $\mathrm{M}$, et al. Intrahepatic micrometastases around liver metastases from gastric cancer. J Hepato Biliary Pancr Surg. (2009) 16:493-501. doi: 10.1007/s00534-009-0081-y

53. Ohkura Y, Shinohara H, Haruta S, Ueno M, Hashimoto M, Sakai Y, et al. Hepatectomy offers superior survival compared with non-surgical treatment for $</=3$ metastatic tumors with diameters $<3 \mathrm{~cm}$ from gastric cancer: a retrospective study. World J Surg. (2015) 39:2757-63. doi: 10.1007/s00268-015-3151-0

54. Okano K, Maeba T, Ishimura K, Karasawa Y, Goda F, Wakabayashi H, et al. Hepatic resection for metastatic tumors from gastric cancer. Ann Surg. (2002) 235:86-91. doi: 10.1097/00000658-200201000-00011

55. Oki E, Tokunaga S, Emi Y, Kusumoto T, Yamamoto M, Fukuzawa K, et al. Surgical treatment of liver metastasis of gastric cancer: a retrospective multicenter cohort study (KSCC1302). Gastr Cancer. (2016) 19:968-76. doi: 10.1007/s10120-015-0530-z

56. Qiu JL, Deng MG, Li W, Zou RH, Li BK, Zheng Y, et al. Hepatic resection for synchronous hepatic metastasis from gastric cancer. Eur J Surg Oncol. (2013) 39:694-700. doi: 10.1016/j.ejso.2013.03.006

57. Roh HR, Suh KS, Lee HJ, Yang HK, Choe KJ, Lee KU. Outcome of hepatic resection for metastatic gastric cancer. Am Surg. (2005) 71:95-9. Available online at: https://chinesesites.library.ingentaconnect.com/contentone/sesc/ tas/2005/00000071/00000002/art00001

58. Rudloff U, Langan RC, Mullinax JE, Beane JD, Steinberg SM, Beresnev $\mathrm{T}$, et al. Impact of maximal cytoreductive surgery plus regional heated intraperitoneal chemotherapy (HIPEC) on outcome of patients with peritoneal carcinomatosis of gastric origin: results of the GYMSSA trial. J Surg Oncol. (2014) 110:275-84. doi: 10.1002/jso.23633
59. Ryu T, Takami Y, Wada Y, Tateishi M, Matsushima H, Yoshitomi M, et al. Oncological outcomes after hepatic resection and/or surgical microwave ablation for liver metastasis from gastric cancer. Asian J Surg. (2019) 42:100-5. doi: 10.1016/j.asjsur.2017.09.005

60. Saiura A, Umekita N, Inoue S, Maeshiro T, Miyamoto S, Matsui Y, et al. Clinicopathological features and outcome of hepatic resection for liver metastasis from gastric cancer. Hepatogastroenterology. (2002) 49:1062-65.

61. Sakamoto Y, Sano T, Shimada K, Esaki M, Saka M, Fukagawa T, et al. Favorable indications for hepatectomy in patients with liver metastasis from gastric cancer. J Surg Oncol. (2007) 95:534-9. doi: 10.1002/jso.20739

62. Schildberg CW, Croner R, Merkel S, Schellerer V, Müller V, Yedibela $S$, et al. Outcome of operative therapy of hepatic metastatic stomach carcinoma: a retrospective analysis. World J Surg. (2012) 36:872-8. doi: $10.1007 / \mathrm{s} 00268-012-1492-5$

63. Shinohara T, Maeda Y, Hamada T, Futakawa N. Survival benefit of surgical treatment for liver metastases from gastric cancer. J Gastrointest Surg. (2015) 19:1043-51. doi: 10.1007/s11605-015-2775-6

64. Shirabe K, Shimada M, Matsumata T, Higashi H, Yakeishi Y, Wakiyama S, et al. Analysis of the prognostic factors for liver metastasis of gastric cancer after hepatic resection: a multi-institutional study of the indications for resection. Hepatogastroenterology. (2003) 50:1560-3.

65. Song A, Zhang X, Yu F, Li D, Shao W, Zhou Y. Surgical resection for hepatic metastasis from gastric cancer: a multi- institution study. Oncotarget. (2017) 8:71147-53. doi: 10.18632/oncotarget.16705

66. Takemura N, Saiura A, Koga R, Arita J, Yoshioka R, Ono Y, et al. Long-term outcomes after surgical resection for gastric cancer liver metastasis: an analysis of 64 macroscopically complete resections. Langenbeck's Arch Surg. (2012) 397:951-7. doi: 10.1007/s00423-012-0959-z

67. Tiberio GA, Ministrini S, Gardini A, Marrelli D, Marchet A, Cipollari C, et al. Factors influencing survival after hepatectomy for metastases from gastric cancer. Eur J Surg Oncol. (2016) 42:1229-35. doi: 10.1016/j.ejso.2016.03.030

68. Tsujimoto H, Ichikura T, Ono S, Sugasawa H, Hiraki S, Sakamoto N, et al. Outcomes for patients following hepatic resection of metastatic tumors from gastric cancer. Hepatol Int. (2010) 4:406-13. doi: 10.1007/s12072-009-9161-y

69. Ueda K, Iwahashi M, Nakamori M, Nakamura M, Naka T, Ishida K, et al. Analysis of the prognostic factors and evaluation of surgical treatment for synchronous liver metastases from gastric cancer. Langenbeck's Arch Surg. (2009) 394:647-53. doi: 10.1007/s00423-008-0311-9

70. Viganò L, Vellone M, Ferrero A, Giuliante F, Nuzzo G, Capussotti L. Liver resection for gastric cancer metastases. Hepatogastroenterology. (2013) 60:557-62. doi: 10.5754/hge11187

71. Wang YN, Shen KT, Ling JQ, Gao XD, Hou YY, Wang XF, et al. Prognostic analysis of combined curative resection of the stomach and liver lesions in 30 gastric cancer patients with synchronous liver metastases. BMC Surg. (2012) 12:20. doi: $10.1186 / 1471-2482-12-20$

72. Wang W, Liang H, Zhang H, Wang X, Xue Q, Zhang R. Prognostic significance of radical surgical treatment for gastric cancer patients with synchronous liver metastases. Med Oncol. (2014) 31:258. doi: 10.1007/s12032-014-0258-3

73. Zacherl J, Zacherl M, Scheuba C, Steininger R, Wenzl E, Mühlbacher $\mathrm{F}$, et al. Analysis of hepatic resection of metastasis originating from gastric adenocarcinoma. J Gastrointest Surg. (2002) 6:682-9. doi: 10.1016/S1091-255X(01)00075-0

74. Liao YY, Peng NF, Long D, Yu PC, Zhang S, Zhong JH, et al. Hepatectomy for liver metastases from gastric cancer: a systematic review. BMC Surg. (2017) 17:14. doi: 10.1186/s12893-017-0215-0

75. Kataoka K, Kinoshita T, Moehler M, Mauer M, Shitara K, Wagner AD, et al. Current management of liver metastases from gastric cancer: what is common practice? New challenge of EORTC and JCOG. Gastr Cancer. (2017) 20:904-12. doi: 10.1007/s10120-017-0696-7

76. Al-Batran SE, Goetze TO, Mueller DW, Vogel A, Winkler M, Lorenzen S, et al. The RENAISSANCE (AIO-FLOT5) trial: effect of chemotherapy alone vs. chemotherapy followed by surgical resection on survival and quality of life in patients with limited-metastatic adenocarcinoma of the stomach or esophagogastric junction - a phase III trial of the German AIO/CAOV/CAOGI. BMC Cancer. (2017) 17:893. doi: 10.1186/s12885-017-3918-9

77. Zaanan A, Bouché O, Benhaim L, Buecher B, Chapelle N, Dubreuil $\mathrm{O}$, et al. Gastric cancer: French intergroup clinical practice guidelines 
for diagnosis, treatments and follow-up (SNFGE, FFCD, GERCOR, UNICANCER, SFCD, SFED, SFRO). Digest Liver Dis. (2018) 50:768-79. doi: 10.1016/j.dld.2018.04.025

78. Tiberio GA, Baiocchi GL, Morgagni P, Marrelli D, Marchet A, Cipollari C, et al. Gastric cancer 494 and synchronous hepatic metastases: is it possible to recognize candidates to R0 resection? Ann Surg Oncol. (2015) 22:589-96. doi: 10.1245/s10434-014-4018-6

79. Tiberio GA, Coniglio A, Marchet A, Marrelli D, Giacopuzzi S, Baiocchi L, et al. Metachronous hepatic metastases from gastric carcinoma: a multicentric survey. Eur J Surg Oncol. (2009) 35:486-91. doi: 10.1016/j.ejso.2008.12.017

80. Carmona-Bayonas A, Jiménez-Fonseca P, Echavarria I, Sánchez Cánovas M, Aguado G, Gallego J, et al. Surgery for metastases for esophageal-gastric cancer in the real world: data from the AGAMENON national registry. Eur J Surg Oncol. (2018) 44:1191-8. doi: 10.1016/j.ejso.2018.03.019

81. Shirasu H, Tsushima T, Kawahira M, Kawai S, Kawakami T, Kito Y, et al. Role of hepatectomy in gastric cancer with multiple liver-limited metastases. Gastr Cancer. (2018) 21:338-44. doi: 10.1007/s10120-017-0730-9

82. Yamaguchi $\mathrm{K}$, Yoshida $\mathrm{K}$, Tanahashi $\mathrm{T}$, Takahashi $\mathrm{T}$, Matsuhashi $\mathrm{N}$, Tanaka Y, et al. The long-term survival of stage IV gastric cancer patients with conversion therapy. Gastr Cancer. (2018) 21:315-23. doi: $10.1007 /$ s10120-017-0738-1

83. Yoshida $\mathrm{K}$, Yamaguchi $\mathrm{K}$, Okumura $\mathrm{N}$, Tanahashi $\mathrm{T}$, Kodera $\mathrm{Y}$. Is conversion therapy possible in stage IV gastric cancer: the proposal of new biological categories of classification. Gastr Cancer. (2016) 19:329-38. doi: 10.1007/s10120-015-0575-z

84. Fukuchi M, Ishiguro T, Ogata K, Suzuki O, Kumagai Y, Ishibashi K, et al. Prognostic role of conversion surgery for unresectable gastric cancer. Ann Surg Oncol. (2015) 22:3618-24. doi: 10.1245/s10434-015-4422-6

85. Ikeguchi M, Miyake T, Matsunaga T, Yamamoto M, Fukumoto Y, Yamada Y, et al. Recent results of therapy for scirrhous gastric cancer. Surg Today. (2009) 39:290-4. doi: 10.1007/s00595-008-3860-1

86. Cancer Genome Atlas Research Network. Comprehensive molecular characterization of gastric adenocarcinoma. Nature. (2014) 513:202-9. doi: $10.1038 /$ nature13480
87. Kitayama J, Ishigami H, Yamaguchi H, Yamashita H, Emoto S, Kaisaki S, et al. Salvage gastrectomy after intravenous and intraperitoneal paclitaxel (PTX) administration with oral S-1 for peritoneal dissemination of advanced gastric cancer with malignant ascites. Ann Surg Oncol. (2014) 21:539-46. doi: 10.1245/s10434-0133208-y

88. Tey J, Zheng H, Soon YY, Leong CN, Koh WY, Lim K, et al. Palliative radiotherapy in symptomatic locally advanced gastric cancer: a phase II trial. Cancer Med. (2019) 8:1447-58. doi: 10.1002/cam4.2021

89. Bijlsma MF, Sadanandam A, Tan P, Vermeulen L. Molecular subtypes in cancers of the gastrointestinal tract. Nat Rev Gastroenterol Hepatol. (2017) 14:333-42. doi: 10.1038/nrgastro.2017.33

90. Van Cutsem E, Sagaert X, Topal B, Haustermans K, Prenen H. Gastric cancer. Lancet. (2016) 388:2654-64. doi: 10.1016/S0140-6736(16) 30354-3

91. Koukourakis GV. Evidence based radiation therapy for locally advanced resectable and unresectable gastric cancer. World J Gastrointest Oncol. (2011) 3:131-6. doi: 10.4251/wjgo.v3.i9.131

92. Seki H, Ohi H, Ozaki T, Yabusaki H. Hepatic arterial infusion chemotherapy using fluorouracil, epirubicin, and mitomycin C for patients with liver metastases from gastric cancer after treatment failure of systemic S1 plus cisplatin. Acta Radiol. (2016) 57:781-8. doi: 10.1177/028418511 5603247

Conflict of Interest: The authors declare that the research was conducted in the absence of any commercial or financial relationships that could be construed as a potential conflict of interest.

Copyright $\odot 2019$ Luo, Rong and Huang. This is an open-access article distributed under the terms of the Creative Commons Attribution License (CC BY). The use, distribution or reproduction in other forums is permitted, provided the original author(s) and the copyright owner(s) are credited and that the original publication in this journal is cited, in accordance with accepted academic practice. No use, distribution or reproduction is permitted which does not comply with these terms. 